(Jurnal Teknologi Komputer dan Sistem Informasi)

Februari 2021, Vol 1, No 1, Hlm. 40-45

Available online at http://jurnal.goretanpena.com/index.php/teknisi

\title{
PERANCANGAN SISTEM INFORMASI PENCARIAN KERUSAKAN SEPEDA MOTOR SISTEM ELECTRONIC FUEL IGNATION (EFI)
}

\author{
Muhammad Isnaini ${ }^{1}$, Saut Matedius Situmorang ${ }^{2}$ \\ ${ }^{1,2}$ Fakultas Teknik/ Prodi Teknik Elektro Universitas Efarina \\ Email: Isnainimuhammad@gmail.com
}

\begin{abstract}
Have researched a sistym information about malfunction problems sitem search motor cycle which the device uses advanced methods of reasoning in expert systems. Troubelshooting on motor cycle generally used manually, by determining the symptoms theoretically derived from the experiences so that a technician and student I student often neglected problem finding time and accuracy in solving the problems of motor cycle with EFI sistem repair problems. The method used is the observation on trouble shooting to EFI sensor sistem and collect data from any symptoms of damage to television later in the evaluation of the raw data is entered into a database to an expert system by utilizing visual basic programming.The results will produce a search expert software system that can damage on EFI sensor sparepart can help the technicians and users of the motor cycle itself to recognize and deal damage that occurs EFI component sistem.
\end{abstract}

Keywords: Expert systems, troubleshooting, motor ycle, EFI, damage

\section{PENDAHULUAN}

Beberapa tahun terakhir ini, telah banyak pabrikan kendaraan mengaplikasikan teknologi injeksi bahan bakar di setiap produknya. Beberapa produsen otomotif khususnya sepeda motor memberi namanya macam-macam dan memberi kesan canggih, namun tetap bersistem kerja injection. Teknologi EFI (Electronic Fuel Injection) sebenarnya tidak dapat dikatakan sebagai teknologi yang terbaru, karena teknologi ini sudah diterapkan beberapa tahun lalu. Dan EFI sebenarnya baru diterapkan pada kendaraan keluaran dasawarsa 1990-an. Penggunaan EFI saat itu masih terbatas pada jenis mobil sedan (passenger car). Baru di akhir 1990-an dan awal 2000, kendaraan tipe minivan seperti Kijang atau SUV ikut mengadopsi, pada tahun 2010 muncullah teknologi mesin PGMFI digunakan pada sepeda motor. Pada era sekarang istilah EFI mulai memperoleh saingan: PGM-FI, EPFI,
ECFI, T-DIS, VVT-i, i-VTEC, MIVEC, VANOS, Valvetronic.

Teknologi EFI sebetulnya erat kaitannya dengan sistem manajemen engine (SME). Engine di sini bukan dalam arti mesin, terjemahan dari kata machinery, melainkan motor bakar. Di sinilah bahan bakar minyak (BBM) dicampur dengan udara untuk menghasilkan gaya gerak yang membuat mobil bisa melaju. SME muncul seiring dengan menipisnya persediaan bahan bakar minyak sehingga menuntut engine yang semakin efisien tanpa kehilangan kinerja yang dihasilkannya. Selain itu juga adanya tuntutan untuk memperbaiki kualitas lingkungan hidup, terutama akibat polusi udara. Untuk mencapai tujuan itu, para pabrikan berlomba-lomba mencari dan menerapkan banyak teknologi baru. Mulai dari peralatan dan perlengkapan yang digunakan untuk mendesain engine, pencarian dan penggunaan material baru, 
terobosan dalam proses produksi, dan yang terpenting, campur tangan kontrol elektronik dan komputer untuk mengatur kinerja engine dan peralatan pendukungnya. Engine yang ideal membakar jumlah bahan bakar sesuai dengan kebutuhan serta menyalakan busi pada saat yang tepat sesuai dengan kondisi operasi. Dari sini didapatkan efisiensi pemakaian bahan bakar yang optimal pada setiap kondisi operasi dari engine. Kondisi ini akan menghasilkan emisi gas buang lebihbaik. Sebelum muncul sistem EFI, untuk mencampur bahan bakar dengan udara digunakan karburator. Dalam karburator ini bahan bakar dikabutkan sebagai akibat dari isapan vakum dari venturi. Proses ini mirip semprotan obat nyamuk bertipe pompa. Namun, sebagai alat yang murni mekanikal, karburator punya keterbatasan sehingga hanya efektif pada daerah operasi tertentu.

Dari perkembangan teknologi sistem engine pada sepeda motor diatas harus di ikuti dengan perkembangan sumberdaya dalam melakukan perbaikan dan perawatan sepeda motor dengan teknolgi electronic ignation dimana cara kerja sistem pembakaran bensin berbeda dengan karburator. Untuk perlu penanganan secara khusus dalam melakukan perbaikan dan perawatan pada sistem EFI. Untuk menambah pemahaman Teknisi tentang teknologi EFI pada sepeda motor maka dalam penelitian ini kami mencoba membuat sebuah software yang memuat tentang informasi sistem pakar pencarian kerusakan sepeda motor EFI, dimana terlebih dahulu melakukan observasi pengumpulan data dari sepeda motor berteknologi PGM-FI di bengkel sepeda motor politeknik santo Thomas medan

\section{Kecerdasan Buatan}

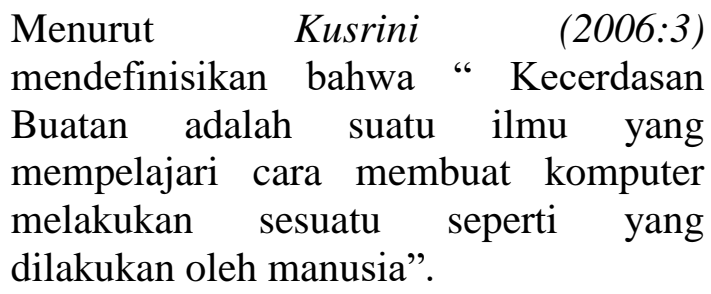

Bagian utama aplikasi Artificial Intelligence adalah pengetahuan (knowledge), suatu pengertian tentang beberapa wilayah subjek yang diperoleh melalui pendidikan dan pengalaman. Walaupun komputer tidak mungkin mendapat pengalaman atau belajar dan meneliti seperti manusia, tapi komputer dapat memperoleh pengetahuan yang dibutuhkannya itu melalui upaya yang diberikan oleh seorang pakar.

Pengetahuan terdiri dari fakta, pemikiran, teori, prosedur dan hubungannya satu sama lain. Pengetahuan juga merupakan informasi terorganisasi dan teranalisis agar bisa lebih mudah dimengerti dan bisa diterapkan pada pemecahan masalah dan pengambilan keputusan

Menurut Kusrini (2008:3) "Sistem pakar adalah aplikasi berbasis komputer yang digunakan untuk menyelesaikan masalah sebagaimana yang dipikirkan oleh pakar".

Menurut Hartati Sri dan Sari Iswanti (2008:3) "Sistem pakar adalah salah satu cabang kecerdasan buatan yang menggunakan pengetahuan-pengetahuan khusus yang dimiliki seorang ahli untuk menyelesaikan suatu masalah tertentu".

Menurut Sudarmo Padji (2006:149) "Expert System adalah program komputer yang membantu pengguna (user) memecahkan masalah yang semestinya memerlukan bantuan tenaga ahli.

Pengetahuan sistem pakar dibentuk dari kaidah atau pengalaman tentang elemen dari bidang pengetahuan tertentu. Pengetahuan pada sistem pakar diperoleh dari orang yang mempunyai pengetahuan 
Available online at http://jurnal.goretanpena.com/index.php/teknisi

pada suatu bidang tertentu, buku-buku, jurnal ilmiah, majalah, media cetak dan juga internet. Pengetahuan-pengetahuan tersebut direpresentasikan dalam format tertentu dan dihimpun dalam suatu basis pengetahuan. Basis pengetahuan ini selanjutnya dipakai sistem pakar untuk menentukan penalaran atas masalah yang dihadapinya

\section{Konsep Dasar Sistem Pakar}

Untuk membangun sistem pakar maka komponen-komponen yang harus dipenuhi adalah sebagai berikut :

1. Antar muka pengguna (User Interface)

2. Basis pengetahuan (Knowledge Base)

3. Mesin inferensi (Inferensi Machine)

4. Memory Kerja (Working memory)

5. Fasilitas Penjelasan (Explanation Facility)

6. Fasilitas Akuisisi Pengetahuan

(Knowledge Acqucition Facility)

Menurut Haryanto Dwi (2001:100), "Troubleshooting adalah sebuah bentuk pemecahan masalah pada suatu sistem yang sedang mengalami gangguan yaitu dengan mencari sumber yang menjadi penyebab masalah tersebut dan kemudian mencari pemecahan atas permasalahan yang terjadi sehingga sistem tersebut bisa beroperasi kembali secara normal".

\section{Sepeda Motor}

Sepeda Motor adalah "kendaraan bermotor beroda dua, atau tiga tanpa rumah-rumah, baik dengan atau tanpa kereta samping". ( sumber : dari materi training HONDA). Sepeda Motor mempunyai Tiga Anatomi Sepeda Motor antara lain

- FRAME / RANGKA

rangka, body cover, tempat duduk (jok), tangki bensin, knalpot

- ELECTRICAL / KELISTRIKAN lampu-lampu, saklar pengatur, panel speedometer, pengatur pengapian/CDI, pengisian battery.

\section{- ENGINE / MESIN}

Sebagai penggerak dapat bertenaga listrik atau mesin bakar (combution engine) dengan transmisi manual maupun semi otomatis umumnya terdiri dari 2 type kategori;

a. Mesin Vertical (GL series, CS-1, Mega Pro, \& Tiger)

b. Mesin Horizontal (Cub, Win \& AT)

\section{PGM-FI Sepeda Motor (Programade} fuel injection)

Istilah sistem injeksi bahan bakar PGMFI dapat digambarkan sebagai suatu sistem yang menyalurkan bahan bakar dengan menggunakan pompa dengan tekanan tertentu untuk mencampur dengan udara yang masuk ke ruang bakar. Pada sistem PGM-FI umumnya proses penginjeksian bahan bakar terjadi di bagian ujung intake manifold, sebelum inlet valve (katup/klep masuk). Pada saat inlet valve terbuka, udara yang masuk ke ruang bakar sudah bercampur dengan bahan bakar.

System PGM-FI harus dapat mensuplai dengan sesuai jumlah bahan bakar yangakan disemprotkan agar dapat bercampur dengan udara dengan perbandingan campuran yang tepat dan sesuai dengan kondisi, putaran, beban mesin, suhu kerja mesin dan suhu atmosfir saat itu.Sistem PGM-FI harus dapat mensuplai jumlah bahan bakar yang bervariasi, agar perubahan kondisi operasi kerja mesin tersebut dapat dicapai dengan unjuk kerja mesin yang tetap optimal.

\section{METODE}

Metode penelitian yang dilakukan peneliti dalam pembuatan sistem pakar ini adalah: 
1. Penelitian Kepustakaan (Library Research): Membaca buku, artikel, majalah yang berhubungan dengan sepeda motor berteknologi PGM-FI

2. Observasi Untuk mendapatkan data tentang tipe, jenis kerusakan pada bagian engine sepeda motor maka terlebih dahulu mengadakan pengamatan langsung dengan cara diagnose pada setiap kemungkinan kerusakan yang terjadi pada setiap komponen PGM-FI. Bagian komponen yang akan di diagnose antara lain:

\section{- ECU (Electrical Control Unit)}

Pusat pengolah data kondisi penggunaan mesin, mendapat masukkan/input dari sensor-sensor mengolahnya kemudian memberi keluaran/output untuk saat dan jumlah injeksi, saat pengapian.

- Fuel Pump

Menghasilkan tekanan BBM yang siap diinjeksikan.

\section{- Presusre Regulator}

Mengatur kondisi tekanan BBM selalu tetap (55 60psi).

\section{- Temperature Sensor}

Memberi masukan ke ECU kondisi suhu mesin, kondisi mesin dingin membutuhkan BBM lebih banyak.

\section{- Inlet Air Temperature Sensor}

Memberi masukan ke ECU kondisi suhu udara yang akan masuk ke mesin, udara dingin $\mathrm{O} 2$ lebih padat, membutuhkan BBM lebih banyak.

\section{- Inlet Air Presure Sensor}

Memberi masukan ke ECU kondisi tekanan udara yang akan masuk ke mesin, udara bertekanan (pada tipe sepedamotor ini hulu saluran masuk ada diantara dua lampu depan) $\mathrm{O} 2$ lebih padat, membutuhkan BBM lebih banyak.

Atmospheric Pressure Sensor memberi masukan ke ECU kondisi tekanan udara lingkungan sekitar sepedamotor, pada dataran rendah (pantai) O2 lebih padat, membutuhkan BBM lebih banyak.

\section{- Crankshaft Sensor}

Memberi masukan ke ECU posisi dan kecepatan putaran mesin, putaran tinggi membutuhkan buka INJECTOR yang lebih cepat.

\section{- CamShaft Sensor}

Memberi masukan ke ECU posisi langkah mesin, hanya langkah hisap yang membutuhkan buka INJECTOR.

- Throole Sensor

Memberi masukan ke ECU posisi dan besarnya bukaan aliran udara, bukaan besar membutuhkan buka INJECTOR yang lebih lama.

\section{- Fuel Injector}

Gerbang akhir dari BBM yang bertekanan, fungsi utama menyemprotkan BBM ke dalam mesin, membuka dan menutup berdasarkan perintah dari ECU.

\section{- Speed Sensor}

Memberi masukan ke ECU kondisi kecepatan sepedamotor, memainkan gas di lampu merah dibanding kecepatan $90 \mathrm{~km} / \mathrm{jam}$, buka INJECTOR berbeda.

\section{- Vehicle Sensor}

Memberi masukan ke ECU kondisi sepedamotor, jika motor terjatuh dengan kondisi mesin hidup maka ECU akan menghentikan kerja FUEL PUMP, IGNITION, INJECTOR, untuk keamanan dan keselamatan.

Setelah mendapat data-data pada setiap komponen diatas maka akan dilakukan pembuatan database. Selanjutnya membuat system pakar dengan menerapkan teori kecerdasan buatan dan menganalisa hasil dengan membandingkan hasil informasi yang diperoleh dari system pakar dengan kejadian nyata yang dihasilkan trainer televis 
(Jurnal Teknologi Komputer dan Sistem Informasi)

Februari 2021, Vol 1, No 1, Hlm. 40-45

Available online at http://jurnal.goretanpena.com/index.php/teknisi

Berikut ini adalah diagram konteks perancangan software pakar pencarian kerusakan sepeda motor PGM-FI

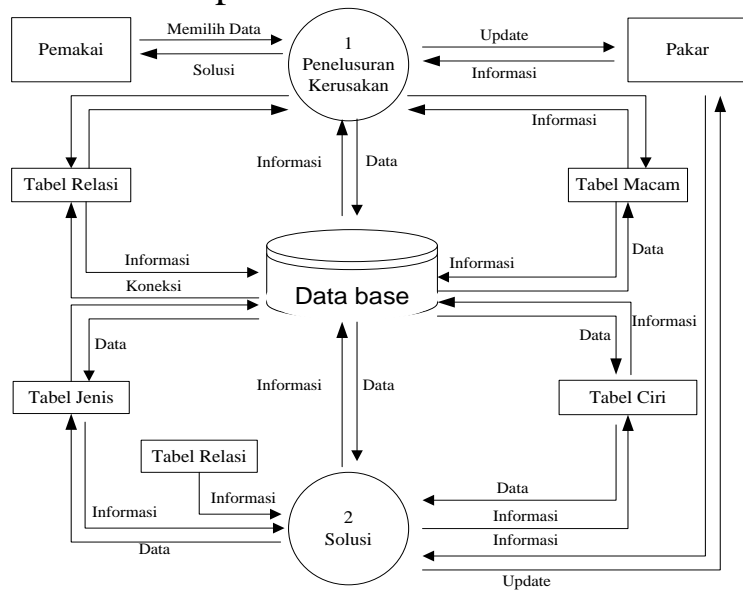

Gambar 1 Data Flow Diagram perancangan Software pencarian kerusakan sepeda motor PGM FI

\section{HASIL DAN PEMBAHASAN}

\section{Implementasi Sistem}

Implementasi sistem merupakan penerapan sistem dalam menjalankan program yang telah dibuat, sehingga user dapat dengan mudah menjalankan dan mempelajari sistem tersebut. Implementasi dari sistem pakar ini dimulai dari tampilan login hingga form solusi kerusakan sepeda motor.

\section{Form Login}

Form Login adalah merupakan form yang dipakai untuk menentukan user yang akan login ke dalam aplikasi. Tools yang digunakan adalah option button untuk pemilihan user, frame, label, text box dan common button.

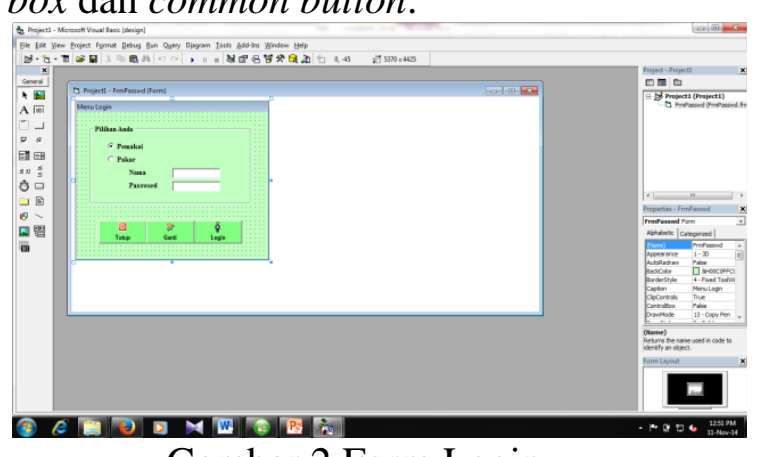

Gambar 2 Form Login

\section{Form Utama Menu Pakar}

Form utama adalah merupakan form yang pertama kali muncul pada saat menjalankan aplikasi sistem pakar setelah login pakar. Terdapat menu-menu yang mempunyai fungsi untuk memanggil form-form atau aplikasi berikutnya maupun fasilitas yang mendukung apilikasi diantaranya adalah basis pengetahuan yang di dalamnya terdapat data macam kerusakan, data jenis kerusakan, data ciri kerusakan sepeda motor sistem EFI dan juga ada basis aturan yang digunakan untuk menambah data macam kerusakan, jenis kerusakan dan ciri kerusakan dan solusinya.

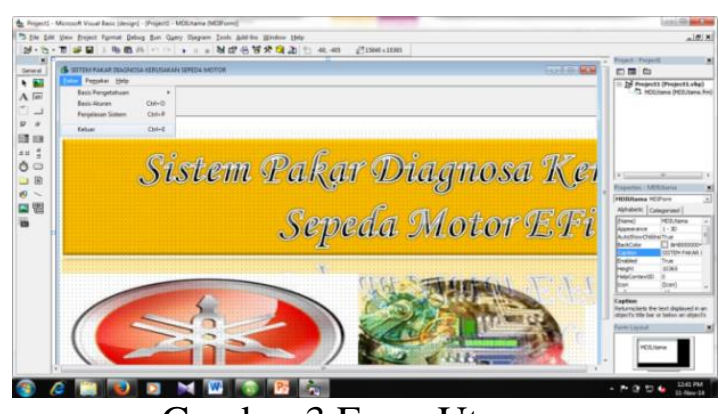

Gambar 3 Form Utama

\section{Form Penelusuran}

Form penelusuran adalah form yang digunakan untuk melakukan penelusuran terhadap kerusakan pada televisi, dimana form ini menggunakan Tools checkbox untuk penelusuran kerusakan, label dan common button pada proses. Bentuk tampilan dari aplikasi ini adalah sebagai berikut :

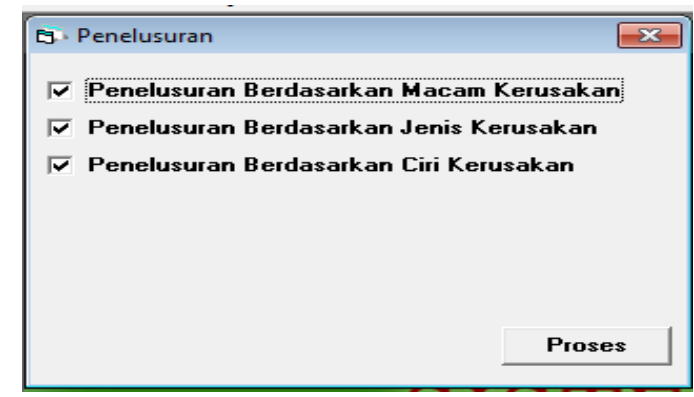

Gambar 4 Tampilan Form Penelusuran 
Form penelusuran macam kerusakan merupakan form yang digunakan untuk melakukan penelusuran terhadap macam kerusakan pada televisi, dimana form ini menggunakan tools combo box untuk penelusuran kerusakan dan common button pada proses.

\section{KESIMPULAN}

Dari pembahasan sampai pada implementasi dari bab-bab dan sub bab sebelumnya maka diperoleh sebuah kesimpulan sebagai berikut :

1. Sistem pakar dapat membantu produktifitas kerja dengan memungkinkan para teknisi sepeda motor sistem EFI yang kurang berpengalaman dapat menelusuri kerusakan serta memperbaikinya dan meminimalisir resiko dalam perbaikan.

2. Troubleshooting Sepeda motor sistem EFI ini dibedakan atas macam kerusakan yang pada umumnya terjadi dan dibagi menjadi jenis-jenis kerusakan berdasarkan blok macam kerusakan komponen utama dan ditentukan cirri kerusakan berdasarkan hasil pengujian pada IMI

3. Membantu para teknisi dalam mengambil keputusan yang tepat tanpa merujuk kepada teknisi pakar yang mungkin sulit dihubungi atau dijumpai.

\section{DAFTAR PUSTAKA}

[1] Desiani Anita, Arhami Muhammad. 2006. Konsep Kecerdasan Buatan. Yogyakarta: Penerbit Andi.

[2] Firdaus. 2004. Pemrograman Database Dengan Visual Basic 6.0 untuk Awam. Bandung : Penerbit, Yrama Widya .

[3] Haryanto Dwi. 2011. Jasa Teknisi Komputer. Bandung : Yrama Widya.
[4]Jogiyanto, Hartono. 2002. Pengenalan Komputer. Yogyakarta : Penerbit Andi.

[5] Kusrini. 2006. Sistem Pakar Teori dan Aplikasi. Yogyakarta : Penerbit Andi.

[6] Madcoms. 2004. Seri Panduan Pemrograman Microsoft Visual basic 6.0. Yogyakarta Penerbit Andi

[7]M. Arhami. 2005. Konsep dasar Sistem Pakar. Yogyakarta : Penerbit Andy

[8]Rusmawan Uus. 2007. Konsep dan Implementasi Visual Basic. Jakarta : PT. Elex Media Komputindo.

[9] Ukar, Kurweni. 2007. Seri Penuntun Praktis Microsoft Access 2007. Jakarta : PT. Elex Media Komputindo.

[10]Wahana Komputer. 2004. Optimalisasi \& Troubleshooting Sistem Komputer. Yogyakarta : Penerbit Andi

[11]http://www.astra-honda.com /index. $\mathrm{php} / \mathrm{katalog} /$ index/4.0/2021

[12] http://sepedamotorsolo11.blogspot.c om/2021/02/pemeriksaan-perbaikansistem-bahan.html 